\title{
Solution for the Location of Rock Cutting Elements Relative to the Rotation Center of Geohod
}

\author{
Valery Nesterov ${ }^{1}$, Vladimr Aksenov ${ }^{2}$, Vladimir Sadovets ${ }^{1}$, and Dmitry Pashkov ${ }^{3, *}$ \\ ${ }^{1}$ T.F. Gorbachev Kuzbass State Technical University, 650000, Kemerovo, Russia \\ ${ }^{2}$ Research Center "Siberian NPO", 650000, Kemerovo, Russia \\ ${ }^{3}$ Institute of Coal of the Federal Research Center Coal and Coal Chemistry Siberian Branch of the \\ RAS, 650610, Kemerovo, Russia
}

\begin{abstract}
The article presents the technical solution for the location of cutting elements relative to the rotation center of Geohod for destructing rocks with a strength up to 1 of Protodyakonov hardness. The relevancy of the research is considered. General information about Geohod is given. The features of working body of Geohod are described, in particular, the formation of a complex shape of the face and the working body, and it is also said that in the case of screw movement of working body of Geohod to the face, the points of working body form a helicoidal (helical) surface. To set the purpose and objectives of the study the geometric parameters of generatrix are justified. The parameter depending on the number of blades and on the radius of location of the blade's cut is identified. Based on the study, the dependence of the number of blades on their location from the center to the periphery is determined. The design of blade working body of Geohod for rocks with a strength $\mathrm{f}<1$ of Protodyakonov hardness is offered. Also the directions for further research have been identified, which include: the development of methods for calculating cutting forces for a technical solution for the location of cutting elements relative to the center of rotation of Geohod for destructing rocks up to 1 of Protodyakonov hardness; the application of this technique for obtaining variants of the blade working body of Geohod of different types.
\end{abstract}

\section{Introduction}

One of the priority directions in the development of science, technology and aquipment in the Russian Federation is the need for effective use of space, including underground space [1]. However, the underground workings are laborious and expensive process in which the most urgent problems are increasing the speed of penetration, labor productivity and safety, reducing the cost of work $[2,3,4]$.

A promising direction that addresses these issues is the application of Geohod technology for making holiow in the underground space where the basic element is Geohod $[5,6,7]$.

\footnotetext{
${ }^{*}$ Corresponding author: pashkov.d.a@inbox.ru
} 
Geohods belong to a new class of tunneling equipment. A distinctive feature of Geohod is screwing of the hull into the rock array, which fulfills the function of the mobile support. In this way, pressure forces are created as a result of the introduction of propulsion elements into the contour array and the use of a normal reaction that occurs when the elements of Geohod interact with the rocks array. Early developments in this area led to the creation of the first samples of Geohods - screw-boring penetrator units (VPA) ELANG-3 and ELANG4 (Fig. 1) $[8,9,10]$. At present, a prototype of Geohod with working body for destructing rocks of medium strength has been created (Figure 2) $[11,12,13,14$.

a)

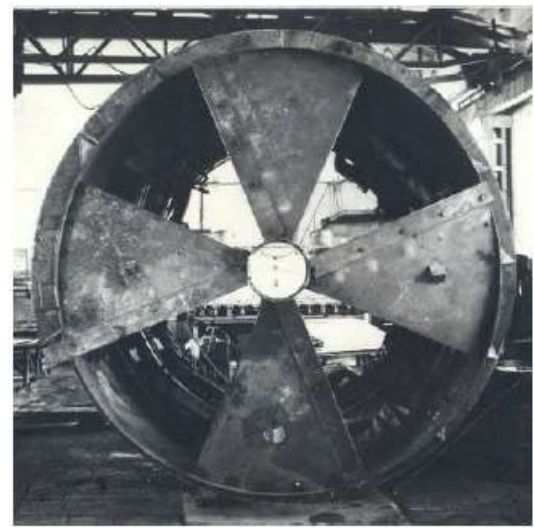

б)

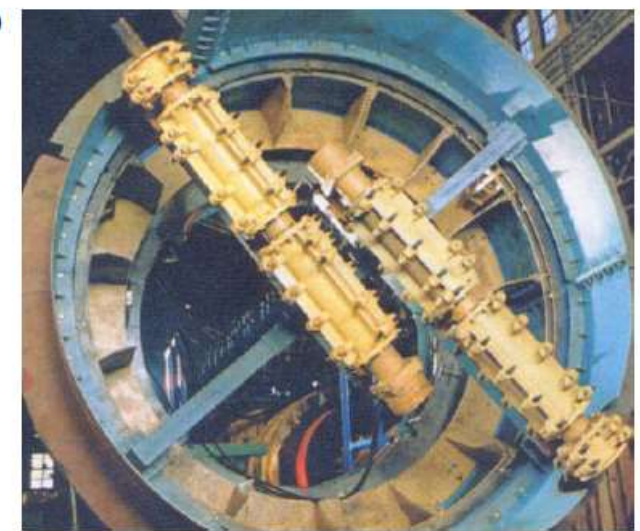

Fig. 1. Experimental samples VPA ELANG-3 (a) and ELANG-4 (b)

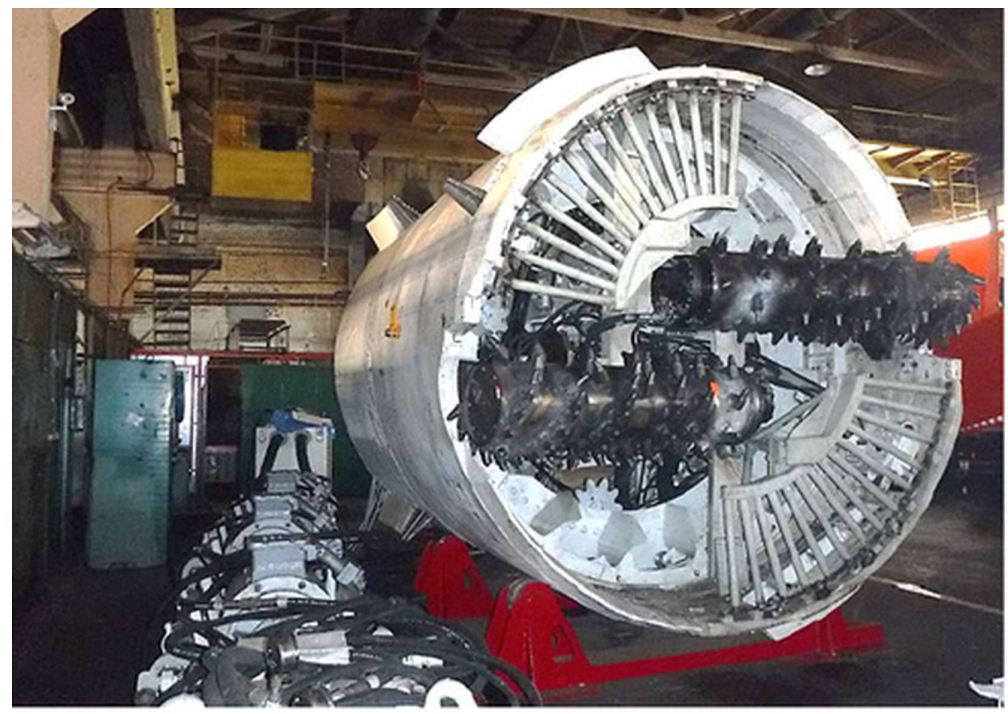

Fig. 2. Experimental sample of Geohod with drum-like working body.

At the current stage of development of the elements of Geohod technology, there are no variants with a variable number of cutting elements depending on the center of Geohod's rotation.

Therefore, the works aimed at developing technical solutions for the location of cutting elements relative to the center of rotation of Geohod for destructing rocks with a strength up to 1 of Protodyakonov hardness are topical. 


\section{The features of working body of Geohod}

The nature of Geohod movement on the face causes the formation of the face with a complex shape. The shape of face is a concentric group of multi-threaded helicoidal surfaces (Figure 3 ), which pitch is equal to the pitch of the helix of propelling device, and the number of hits is equal to the number of destructive elements (bits, drums, blades) located on one radius.

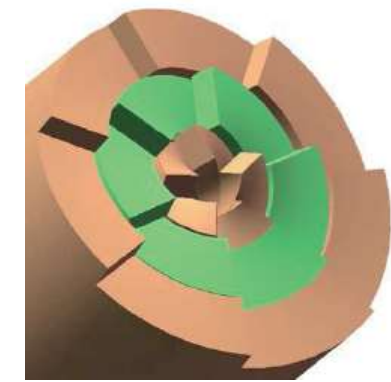

Fig. 3. Concentric group of multi-threaded helicoidal surfaces forming the face of Geohod's working.

When forming such a surface, the tool located on the periphery and the tool located in the inner space move to the face at different angles of inclination to the front working plane [15].

\section{Methods of research}

To solve the problem it is necessary to identify the geometric parameters of generatrix of helicoid.

The geometric parameters of helicoid are the length of generatrix, equal to the radius of the head section (we take $1.6 \mathrm{~m}$ ), and the pitch of helicoid is taken equal to the pitch of helical blade $\left(h_{\mathrm{V}}=0,6 \mathrm{~m}\right)[16]$.

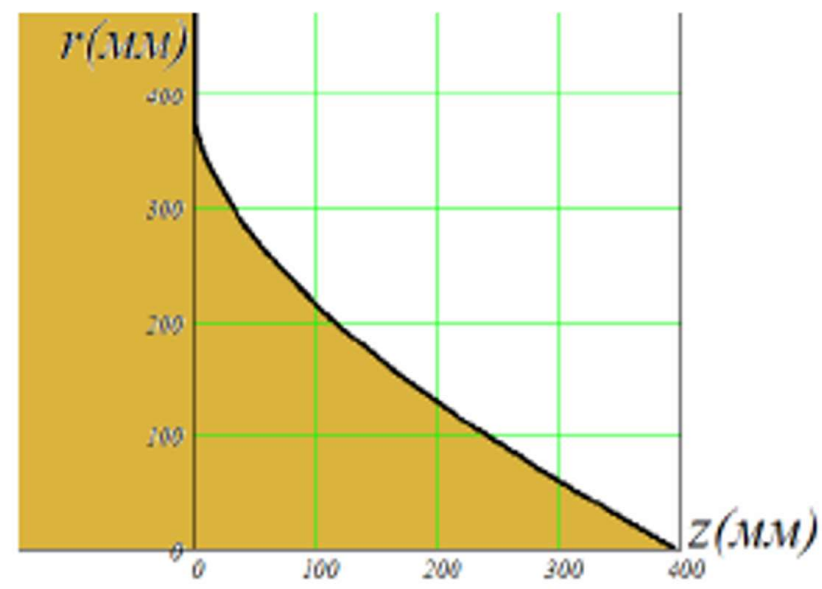

Fig. 4. Rational form of generatrix of the face.

To obtain the geometric shape of the blade of working body in the central part of the face, we use the rational form of generatrix of the face (Figure 4) [17].

In connection with the complex geometric shape, the blade is divided into two parts: the central (the rational form of the face) and the main one. The main part of the blade is located from the radius of generatrix $\left(\mathrm{r}_{0}=0.4 \mathrm{~m}\right)$ to the radius of Geohod $\left(\mathrm{r}_{\mathrm{g}}=1.6 \mathrm{~m}\right)$ (Figure 5). 
Further research is carried out for the main part of the working body blade of Geohod.

The volume of destroyed by this segment rock depends on the number of blades and the radius of location of the blade's segment. Hence, each segment must destroy the same volume:

$$
W^{n} \text { centre }=W^{n} \text { periphery }
$$

For one complete turn of the head section, Geohod will move to the face on the pitch of the helical blade of the external propelling device $h_{\mathrm{V}}$. The volume of the destroyed rock for one turn of the head section of Geohod $W, \mathrm{~m}^{3} /$ turn [8], will be

$$
W=\pi r_{\mathrm{g}}^{2} h_{\mathrm{v}}
$$

The volume of destroyed rock in one turn of the head section of one blade of Geohod working body $W^{\mathrm{n}}, \mathrm{m}^{3} /$ turn, will be

$$
W^{n}=\frac{\pi r_{\mathrm{g}}^{2} h_{\mathrm{v}}}{n}
$$

Any segment of the blade located at the distance $r_{1}$ and $r_{2}$ (Figure 5) from the axis of Geohod rotation in one turn will destroy

$$
W^{n}=\frac{\pi h_{\mathrm{v}}\left(r_{2}^{2}-r_{1}^{2}\right)}{n}
$$

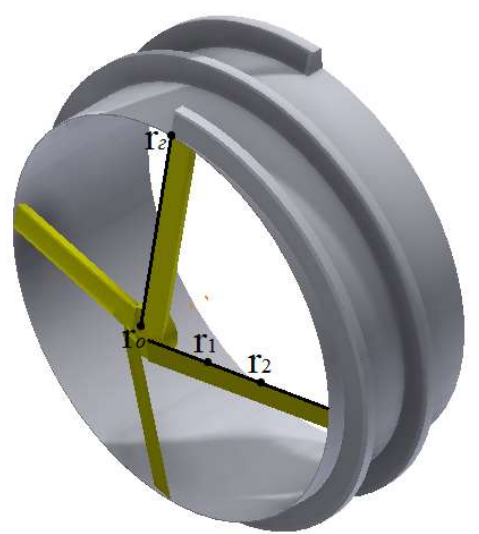

Fig. 5. The scheme of blade working body.

From condition (1) and formula (4) we obtain:

$$
\frac{\pi h_{\mathrm{v}}\left(r_{2}^{2}-r_{0}^{2}\right)}{n_{\text {centre }}}=\frac{\pi h_{\mathrm{v}}\left(r_{\mathrm{g}}^{2}-r_{3}^{2}\right)}{n_{\text {periphery }}}
$$

where $n_{\text {centre }}$ and $n_{\text {periphery }}$ and - the number of blades respectively in the center and on the periphery

From formula (5) we obtain the ratio of the number of blades on the periphery from the number of blades in the center 


$$
\frac{n_{\text {periphery }}}{n_{\text {centre }}}=\frac{\pi h_{\mathrm{v}}\left(r_{\mathrm{g}}^{2}-r_{3}^{2}\right)}{\pi h_{\mathrm{v}}\left(r_{2}^{2}-r_{0}^{2}\right)}
$$

After simplification of formula (6) we obtain:

$$
\frac{n_{\text {periphery }}}{n_{\text {centre }}}=\frac{\left(r_{\mathrm{g}}^{2}-r_{3}^{2}\right)}{\left(r_{2}^{2}-r_{0}^{2}\right)}
$$

To determine the number of blades at the periphery, we take the length of blade's segment between $r_{0}$ and $r_{2}$ equal to the height of the propelling device of Geohod $(0.2 \mathrm{~m})$. That is, we divide the main blade into 6 equal segments.

Since $r_{2}-r_{0}=r_{\mathrm{g}}-r_{3}=0,2 \mathrm{~m}$, the formula (7) will be written as:

$$
\frac{n_{\text {periphery }}}{n_{\text {centre }}}=\frac{r_{\mathrm{g}}+r_{3}}{r_{2}+r_{0}}
$$

From formula (8) we determine the number of blades on the periphery:

$$
n_{\text {peripheryu }}=\frac{r_{\mathrm{g}}+r_{3}}{r_{2}+r_{0}} n_{\text {centre }}
$$

\section{Results}

Each segment moves along its cutting line. From the study [7], the rational number of blades for Geohod working body is in the range from 2 to 12. On the first cutting line (counting from the center) we set 4 blades. Consequently, solving formula (9) we get that 12 blades should be installed on the periphery.

Figure 6 shows the dependence graph of $n=\mathrm{f}(r)$ at $h_{\mathrm{v}}=0.6 \mathrm{~m}$ and $n_{\text {centre }}=4$. Since the number of blades cannot be non-integral, the results obtained by formula (9) were rounded to the integral.

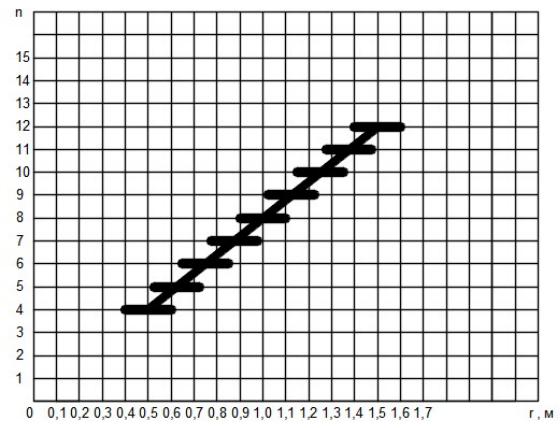

Fig. 6. The dependence graph of the number of blades on the radius of their position.

By approximation of values by the method of least squares the equation of regression of the first degree with the coefficient of determination $R^{2}=1$ is obtained

$$
n=8 r
$$


Taking into account that $n_{\text {centre }}=4$, expression (10) will be written as:

$$
n=2 n_{\text {centre }} r
$$

Figure 7 shows the dependence graph of $n=\mathrm{f}(r)$ at $h_{\mathrm{v}}=0.6 \mathrm{~m}$ and $n_{\text {centre }}=2$. Since the number of blades cannot be non-integral, the results obtained by formula (9) were rounded to the integral.

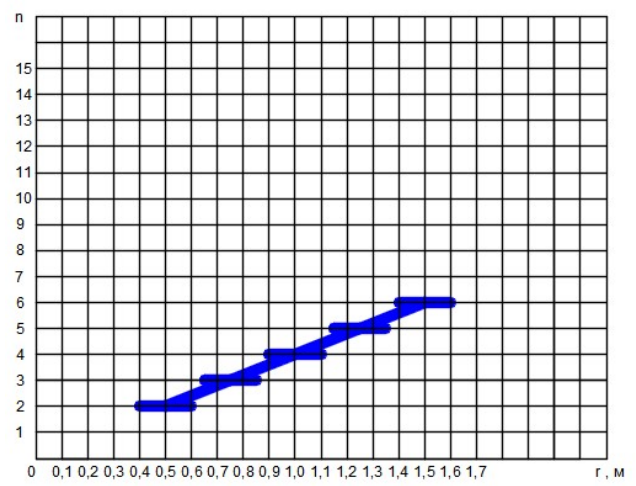

Fig. 7. The dependence graph of the number of blades on the radius of their position

By approximation of values by the method of least squares the equation of regression of the first degree with the coefficient of determination $R^{2}=1$ is obtained

$$
n=4 r
$$

Taking into account that $n_{\text {centre }}=2$, expression (12) will be written as:

$$
n=2 n_{\text {centre }} r
$$

\section{Conclusions}

Since the expressions (11) and (13) are equal, the number of blades on each cutting line will be determined by the expressions (11) and (13). From this we conclude that the number of blades on each cutting line depends on the number of blades in the central cutting line and the radius of the cutting line.

On the basis of this conclusion and the study [7] we proposed the design of blade's working body of Geohod for rocks with a strength $\mathrm{f}<1$ of Protodyakonov hardness (Figure 8). 


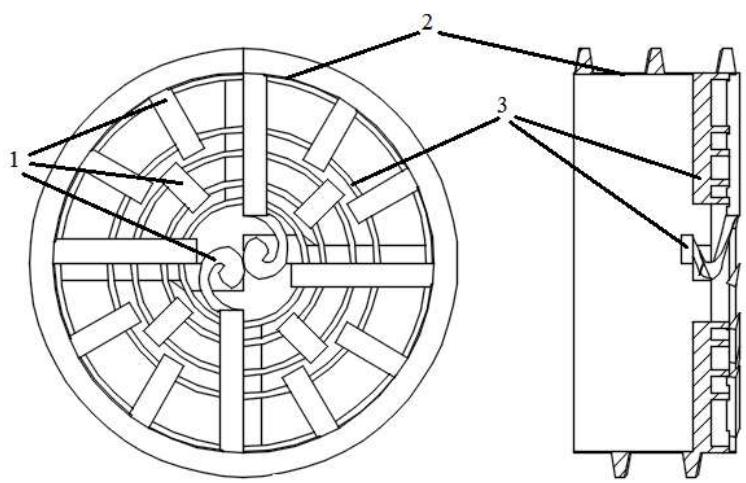

Fig. 8. The blade working body of Geohod for rocks with a strength $\mathrm{f}<1$ of Protodyakonov hardness.1blades, 2-head section of generatrix, 3-supporting elements.

- To develop a technique for calculating the cutting forces for a technical solution for the location of cutting elements relative to the center of rotation of Geohod for destroying rocks with a strength up to 1 of Protodyakonov hardness;

- Apply this technique to obtain variants of the blades for other types of Geohod.

\section{References}

1. V. Aksenov, I. Chicherin, I. Kostinez, A. Kazantsev, A. Efremenkov, E3S Web of Conf., 21, 02020 (2017)

2. B. Maidl, L. Schmid, W. Ritz, M. Herrenknecht, Cutting Machines (Berlin: Ernst\& Sohn, 2008)

3. T. Wighman, Think deep - go underground (ENR, London, 1998)

4. S. Nishi, T. Seiki, Planning and design of underground space use, (Nagoya University press, Nagoya, 1997)

5. R. V. Chernukhin, A. A.Dronov, M. Y. Blashchuk, IOP Conf. Ser.: Mater. Sci. Eng., 91, 012086 (2015)

6. V. Aksenov, V. Sadovets, D. Pashkov, E3S Web of Conf., 21, 02014 (2017)

7. V. Aksenov, V. Sadovets, E. Rezanova, D. Pashkov E3S Web of Conf., 15, 03015 (2017)

8. V.Y. Sadovets, V.Y. Beglyakov, V.V. Aksenov IOP Conference Series: Materials Science and Engineering, 91, 012085 (2015)

9. M.Y. Blashchuk, A.A. Kazantsev, R.V. Chernukhin, Applied Mechanics and Materials, 682, 418 (2014)

10. A.B. Efremenkov, 6th International Forum on Strategic Technology (IFOST - 2011), 1, $348(2011)$

11. V.V. Aksenov, A.B. Efremenkov, V.Y. Beglyakov, Applied Mechanics and Materials, 379, 16 (2013)

12. M.Y. Blaschuk, A.A. Dronov, S.S. Ganovichev, IOP Conf. Ser. Mater. Sci. Eng., 127, 012033 (2016)

13. D.N. Nesteruk, M.V. Momot, V.Yu. Beglyakov, E.V. Politsinskaya, Applied Mechanics and Materials, 756, 709 (2015)

14. R.V. Chernukhin, M.Y. Blaschuk, V.Yu. Blumenstein, P.A. Chazov, IOP Conf. Ser. Mater. Sci. Eng., 142, 012003 (2016) 
15. V.Y. Sadovets, V.Y. Beglyakov, A.B. Efremenkov, Applied Mechanics and Materials, 770, 384 (2015)

16. V.Y. Begljakov, V.Y. Timofeev, M.V. Dokhnenko, Applied Mechanics and Materials, 682, $282(2014)$ 